\title{
METHOD TO TEST FUNGAL DEGRADATION OF BAMBOO AND WOOD USING VERMICULITE AS RESERVOIR FOR MOISTURE AND NUTRIENTS
}

\author{
Dongsheng Wei ${ }^{1, \$}$, Olaf Schmidt ${ }^{1}$, Walter Liese ${ }^{1}$
}

\begin{abstract}
Proposed is a method to investigate degradation of lignocelluloses by pure cultures of basidiomycetes using preserving jars with vermiculite as reservoir for water and nutrients. Bamboo samples of Gigantochloa atroviolacea and Phyllostachys pubescens and wood samples of Fagus sylvatica and Pinus sylvestris were inoculated with the brown-rot fungus Coniophora puteana and the white-rot fungus Schizophyllum commune. The fungi were cultured on vermiculite containing different amounts of tap water or malt extract solution. Mass loss of the bamboos after 32 weeks was low and did not show a remarkable influence of moisture content and nutrient addition. However, considerable degradation of Pinus sylvestris sapwood occurred by $C$. puteana whereby moisture and nutrients influenced aggressiveness.
\end{abstract}

Keywords: Bamboo degradation, vermiculite, moisture content, nutrient addition.

\section{INTRODUCTION}

Bamboo is a fast growing woody grass with increasing importance for sustainable production of materials with many applications for structures and industrial utilization. However, bamboo has a low natural durability and is attacked by fungi during storage, transport, processing and final use (Liese and Kumar 2003). There are several reports on its degradation by fungi (Liese 1959, 1985; Abdurachim 1964, Mohanan 1997, Kim et al. 2011, Suprapti 2010, Ma et al. 2010, Schmidt et al. 2011). The behaviour of bamboo against decay fungi is an important parameter in bamboo establishment and use. Most investigations revealed that bamboo degradation is due to white and soft rot fungi, whereas brown-rot species were less aggressive. Among the investigated fungi, Coniophora puteana and Schizophyllum commune varied with respect to the test method used: Low maximum mass loss was measured on agar under pure culture condition, whereas considerable degradation occurred in the 'fungus cellar test' where the samples are placed in large metal containers on unsterile garden soil with different moisture accessibility (Schmidt et al. 2011). However, C. puteana and S. commune differed in decay activity: C. puteana produced maximum mass loss at low moisture content of $57 \%$, whereas decay by $S$. commune was highest at $182 \%$ moisture content (Schmidt et al. 2011).

Mixed microbial decay in soils with various water holding capacities was studied by Becker and Kaune (1966). Kaune (1970) and Worrall and Wang (1991) used for wood a vermiculite system with pure cultures of soft-rot fungi and proved its suitability for wood degradation tests. Adaskaveg et al. (1991) showed decay of palm wood by basidiomycetes with the vermiculite-block assay. Curling et al. (2002) exposed basidiomycetes to wood in a vermiculite-soil system. The American standard soil-block test ASTM D1413 was not used for our study because it is principally similar to our former fungus cellar test (Schmidt et al. 2011).

The aim of this study was to test bamboo and wood degradation by pure cultures of basidiomycetes with vermiculite as reservoir of moisture and nutrients.

\footnotetext{
' Section Wood Biology, Centre for Wood Science, University of Hamburg, Leuschnerstrasse 91d, 21031 Hamburg, Germany ${ }^{\wedge}$ Corresponding author: dongsheng.wei@uni-hamburg.de Received: 05.11.2012. Accepted: 17.01.2013
} 


\section{MATERIALS AND METHODS}

\section{Fungi}

The brown-rot fungus Coniophora puteana strain 167 from the laboratory collection and the white-rot fungus Schizophyllum commune strain 87 isolated from bamboo (Schmidt et al. 2011) were held on agar plates of 2\% malt extract (Oxoid) and 1.5\% agar (Oxoid).

\section{Bamboo and wood samples}

Bamboo species Gigantochloa atroviolacea and Phyllostachys pubescens were used. Culm sections of $G$. atroviolacea (diameter 5.5-7.0 cm) and P. pubescens (diameter 5.5-6.5 cm) were obtained from CONBAM, Geilenkirchen, Germany and the Bamboo Centre, Baden-Baden, Germany, respectively. Culms were proven with the curcuma-test (Peylo 2001) to ensure that no boron was present which is commonly used against moulding. The samples were cut to $5 \mathrm{~cm}$ length, $2.5 \mathrm{~cm}$ width and $0.5-3.5 \mathrm{~cm}$ wall thickness. Wood samples of Fagus sylvatica and Pinus sylvestris were cut to $5 \mathrm{~cm}$ length, $2.5 \mathrm{~cm}$ width and $1.5 \mathrm{~cm}$ height. Samples were put into a climate room at $20 \pm 2{ }^{\circ} \mathrm{C}$ and $65 \pm 5 \%$ relative humidity (RH) for 4 weeks, weighed, wrapped in plastic (Sengewald Flexopeel, Germany) and send for gamma radiation to BBF sterilization service GmbH (Kernen, Germany). To calculate the initial weight, moisture content at $20^{\circ} \mathrm{C}$ and $65 \%$ was adjusted downward to the oven-dry value.

\section{Vermiculite test}

The decay experiment was performed in $500 \mathrm{ml}$ preserving jars (Fig. 1). Vermiculite of 2-3 mm particle size was obtained from vermiculite-shop (thinex new media, Dortmund, Germany, www.vermiculit-shop.de) and sieved through a $2 \mathrm{~mm}$ sieve. Each preserving jar was filled with $200 \mathrm{ml}$ vermiculite. Tap water or $2 \%$ malt extract solution were added in 80,100,120,140 and $160 \mathrm{ml}$ amounts per jar. The jars covered with glass lids were sterilized in the autoclave at $121^{\circ} \mathrm{C}$ and $210 \mathrm{kPa}$ for $30 \mathrm{~min}$. Each two bamboo or wood samples were put aseptically in one jar. Two jars were used for one fungus. Vermiculite and sample were separated by a metal ring to avoid liquid diffusion in the sample. A plug of the test fungus from agar plates was then placed on the samples top. After 32 weeks of incubation at $20 \pm 2^{\circ} \mathrm{C}$ and $65 \pm 5 \% \mathrm{RH}$, the mycelium was removed from the sample surface, the samples were weighed for final wet weight and oven dried at $103^{\circ} \mathrm{C}$ for 3 days. Mass loss was calculated by weight comparison before and after incubation. Standard deviation for each 4 specimens per treatment group was calculated according to ANOVA, SPSS software 2002.

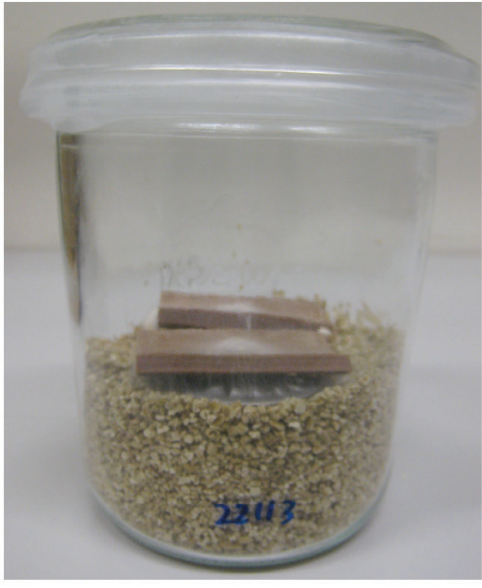

(a)

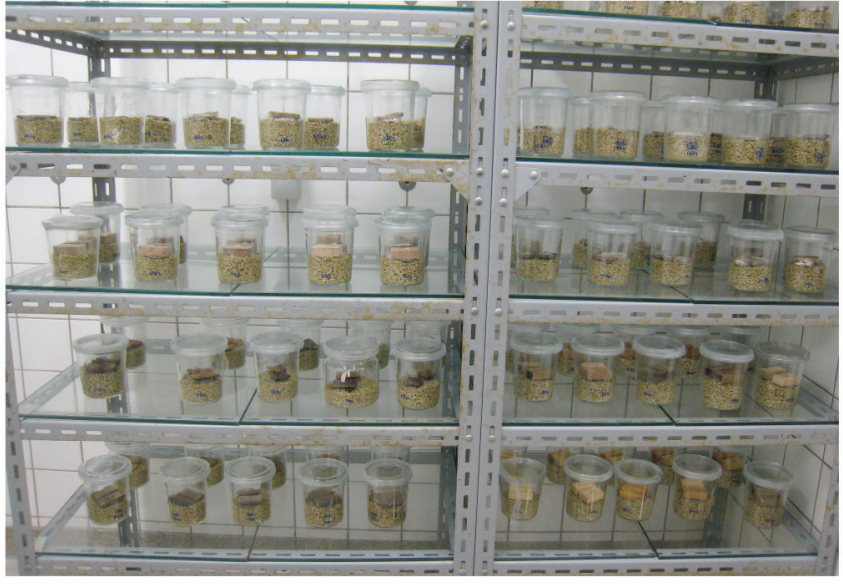

(b)

Figure 1. Vermiculite test setup.

(a) bottle with vermiculite and bamboo samples. (b) incubation room. 


\section{Assessment of fungal growth and vitality test after incubation}

The development of fungal growth on the samples was assessed according to the scheme in table 1 , which values hyphal density and hyphal coverage of sample. After 32 weeks of incubation, portions of overgrown vermiculite were transferred from the jars to malt agar plates to prove the vitality of the mycelium after the vermiculite test.

Table 1. Evaluation scheme for hyphal growth on bamboo and wood samples.

\begin{tabular}{ll|ll}
\hline Hyphal density & Description & Hyphal coverage of & Description \\
\hline 0 & No growth & 0 & No coverage \\
1 & Sparse mycelium & 1 & $1-33 \%$ coverage \\
2 & Normal mycelium & 2 & $34-66 \%$ coverage \\
3 & Thick mycelium & 3 & $67-99 \%$ coverage \\
& & 4 & Total coverage \\
\hline
\end{tabular}

\section{RESULTS AND DISCUSSION}

Figure 2 shows details of fungal growth on bamboo samples and on vermiculite particles.

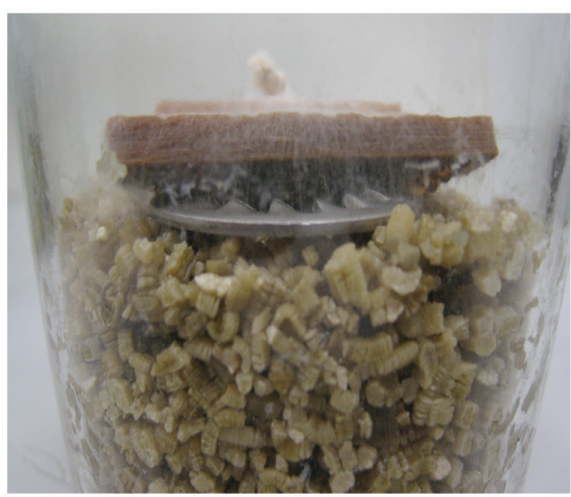

(a)

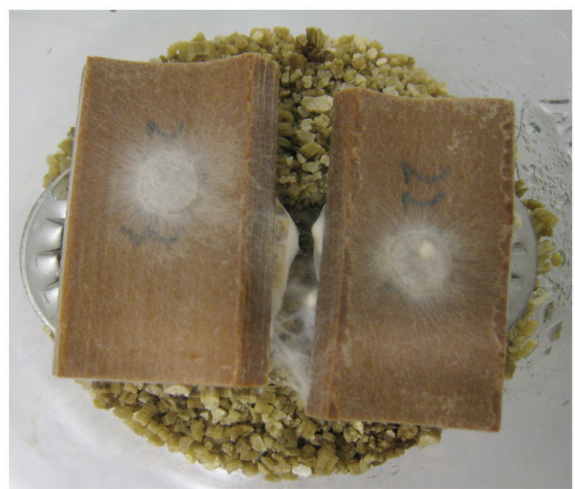

(b)

Figure 2. Details of a preserving jar with mycelium of Schizophyllum commune covering Phyllostachys pubescens samples.

(a) side view. (b) top view.

All bamboo and wood samples were totally covered by mycelium after 32 weeks (Table 2). Hyphal density with tap water was less than with malt extract. However, the density of mycelium is not necessarily related to mass loss in test specimens (Schmidt 2006). 
Table 2. Fungal growth on bamboo and wood samples after 32 weeks incubation.

\begin{tabular}{|c|c|c|c|c|c|c|c|c|c|c|c|c|}
\hline \multirow{3}{*}{ Bamboo } & \multirow{3}{*}{ Fungus } & \multirow{3}{*}{ Liquid } & \multicolumn{10}{|c|}{ Liquid (ml) per preserving jar } \\
\hline & & & \multicolumn{2}{|c|}{80} & \multicolumn{2}{|c|}{100} & \multicolumn{2}{|c|}{120} & \multicolumn{2}{|c|}{140} & \multicolumn{2}{|c|}{160} \\
\hline & & & $\mathrm{D}$ & $\mathrm{C}$ & $\mathrm{D}$ & $\mathrm{C}$ & $\mathrm{D}$ & $\mathrm{C}$ & $\mathrm{D}$ & $\mathrm{C}$ & D & $\mathrm{C}$ \\
\hline \multirow{4}{*}{$\begin{array}{l}\text { Gigantochloa } \\
\text { atroviolacea }\end{array}$} & \multirow{2}{*}{$\begin{array}{l}\text { Coniophora } \\
\text { puteana }\end{array}$} & Tap water & 1 & 4 & 1 & 4 & 1 & 4 & 1 & 4 & 1 & 4 \\
\hline & & Malt extract & 2 & 4 & 2 & 4 & 2 & 4 & 2 & 4 & 2 & 4 \\
\hline & \multirow{2}{*}{$\begin{array}{l}\text { Schizophyllum } \\
\text { commune }\end{array}$} & Tap water & 1 & 4 & 1 & 4 & 1 & 4 & 1 & 4 & 1 & 4 \\
\hline & & Malt extract & 2 & 4 & 2 & 4 & 2 & 4 & 2 & 4 & 2 & 4 \\
\hline \multirow{4}{*}{$\begin{array}{l}\text { Phyllostachys } \\
\text { pubescens }\end{array}$} & \multirow{2}{*}{$\begin{array}{l}\text { Coniophora } \\
\text { puteana }\end{array}$} & Tap water & 1 & 4 & 1 & 4 & 1 & 4 & 1 & 4 & 1 & 4 \\
\hline & & Malt extract & 2 & 4 & 2 & 4 & 2 & 4 & 2 & 4 & 2 & 4 \\
\hline & \multirow{2}{*}{$\begin{array}{l}\text { Schizophyllum } \\
\text { commune }\end{array}$} & Tap water & 1 & 4 & 1 & 4 & 1 & 4 & 1 & 4 & 1 & 4 \\
\hline & & Malt extract & 2 & 4 & 2 & 4 & 2 & 4 & 2 & 4 & 2 & 4 \\
\hline \multirow{2}{*}{$\begin{array}{l}\text { Fagus } \\
\text { sylvatica }\end{array}$} & \multirow{2}{*}{$\begin{array}{l}\text { Schizophyllum } \\
\text { commune }\end{array}$} & Tap water & 1 & 4 & 1 & 4 & 1 & 4 & 1 & 4 & 1 & 4 \\
\hline & & Malt extract & 2 & 4 & 2 & 4 & 2 & 4 & 2 & 4 & 2 & 4 \\
\hline \multirow{2}{*}{$\begin{array}{l}\text { Pinus } \\
\text { sylvestris }\end{array}$} & \multirow{2}{*}{$\begin{array}{l}\text { Coniophora } \\
\text { puteana }\end{array}$} & Tap water & 1 & 4 & 1 & 4 & 1 & 4 & 1 & 4 & 1 & 4 \\
\hline & & Malt extract & 3 & 4 & 3 & 4 & 3 & 4 & 2 & 4 & 2 & 4 \\
\hline
\end{tabular}

$\mathrm{D}=$ hyphal density, $\mathrm{C}=$ hyphal coverage of sample

Results of the degradation tests are summarized in figures 3 and 4. Standard deviation is not shown for the less mass loss by S. commune (Fig. 3), but is shown for C. puteana (Fig. 4) due to its greater decay capacity. Both bamboo species Gigantochloa atroviolacea and Phyllostachys pubescens were rather resistant to degradation by the white-rot fungus $S$. commune and the brown-rot fungus $C$. puteana over 32 weeks of incubation, the first bamboo being more resistant than the latter one. Adding different amounts $(80$ to $160 \mathrm{ml})$ of water or nutrient solution to vermiculite had only small effect. The final bamboo moisture contents were 61 to $84 \%$, which is a suitable range for decay fungi (Schmidt 2006).

Figure 3 shows the results for $S$. commune. Maximum mass loss of bamboo was only $4.6 \%$. Thus, possible influences among the parameters, bamboo species, moisture content and nutrient addition, were rather indistinct for this fungus. Low decay was also measured on agar in preserving jars and in Kolle flasks (Schmidt et al. 2011) which was already reported by Suprapti (2010) and Kim et al. (2011). Abdurachim (1964) obtained 15\% mass loss in Gigantochloa apus. Also beech wood showed neglectable decay (0.7-2 \%) by S. commune (Fig. 3), which corresponds to previous results on low degradation of wood samples (Schmidt and Liese 1978). However, this fungus is common on bamboo culms during storage and use (Liese 1985, Mohanan 1997, Liese and Kumar 2003). 


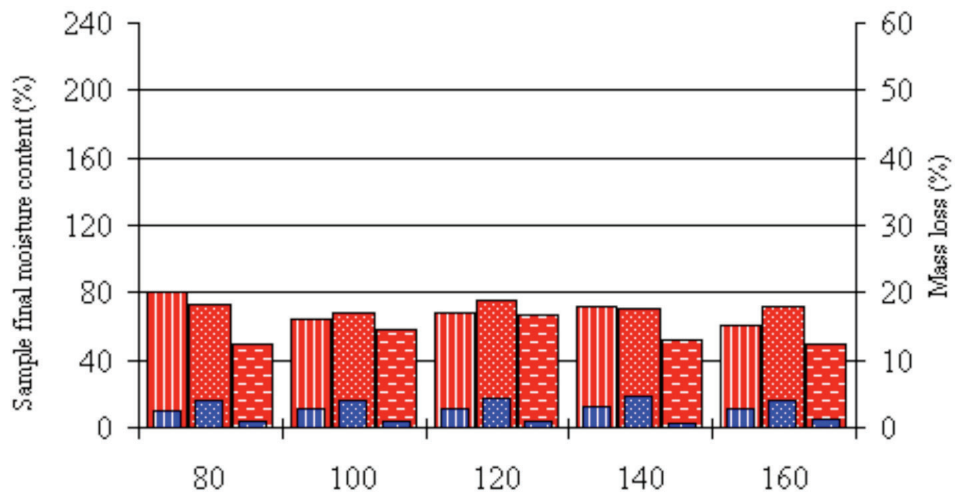

(a)

Liquid Added (ml)

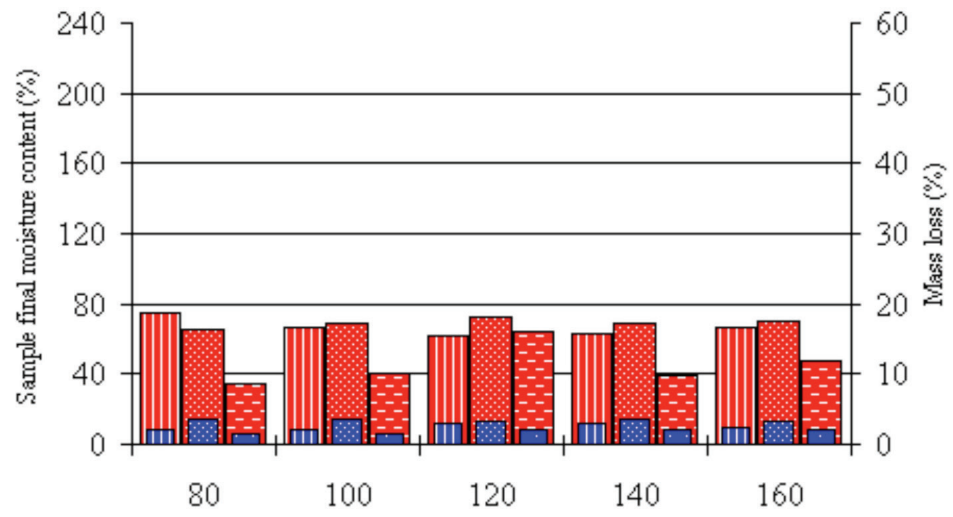

(b)

Liquid Added (ml)

\begin{tabular}{|c|c|}
\hline Sarmple firal moisture content & Mass loss \\
\hline DI Gigantochloa atroviolacea & II Gigantochloa atroviolacea \\
\hline Phyllostachys pubescens & Phyllostachys pubescens \\
\hline Fagus sylvatica & - Fagus sylvatica \\
\hline
\end{tabular}

Figure 3. Influence of moisture content and nutrients on mass loss by Schizophyllum commune. (a) incubation with tap water. (b) incubation with malt extract solution. 


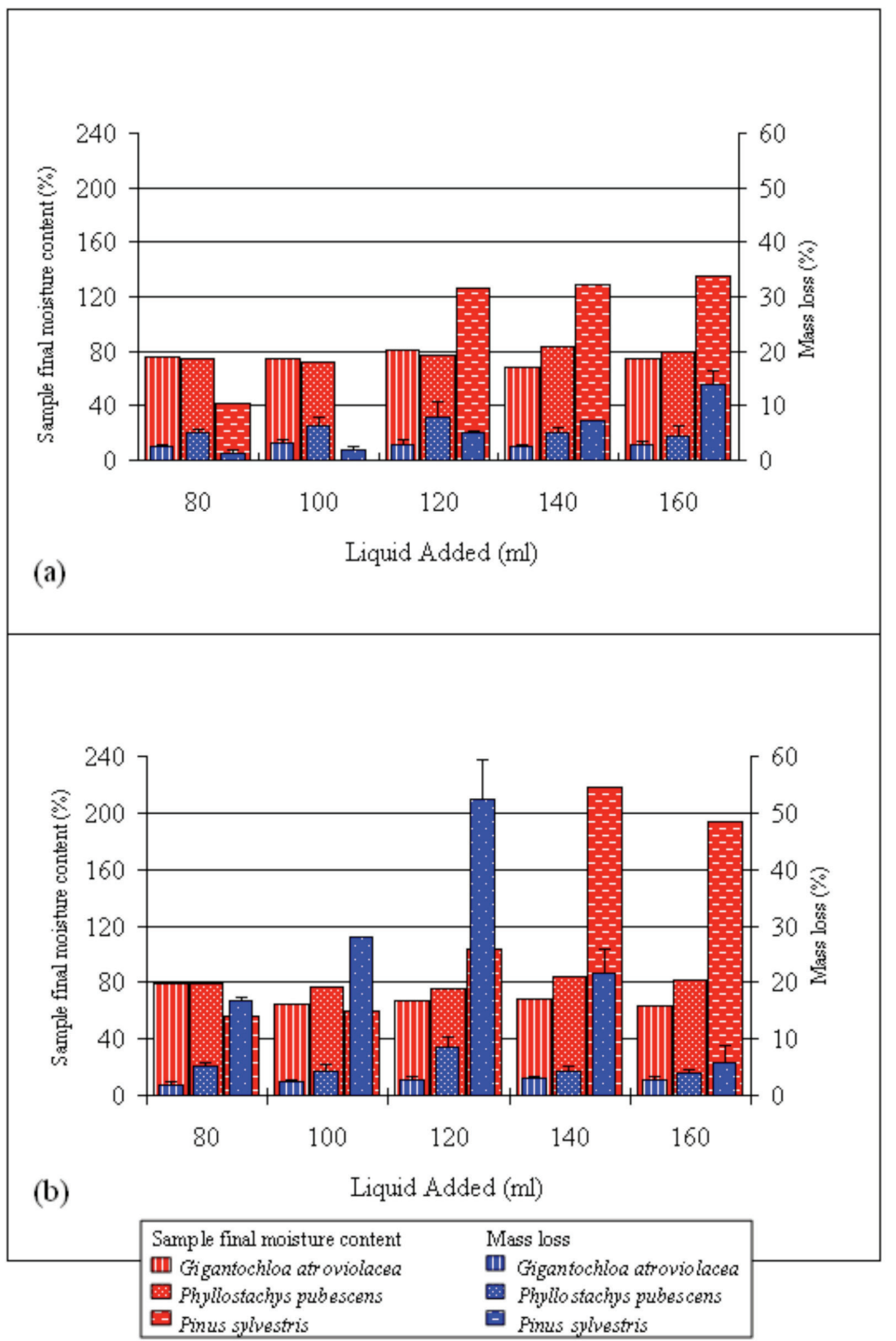

Figure 4. Influence of moisture content and nutrients on mass loss by Coniophora puteana.

(a) incubation with tap water. (b) incubation with malt extract solution.

Figure 4 shows the results for $C$. puteana. Maximum mass loss of bamboo was $8.4 \%$, whereby $P$. pubescens was more decayed than G. gigantochloa. Both liquid additions, tap water and malt extract, increased mass loss from 80 - to $120 \mathrm{ml}$-addition followed by decrease to $160 \mathrm{ml}$. Scots pine wood revealed significant differences among the liquid additions: With tap water, decay increased stepwise to $14.0 \%$ maximum at $160 \mathrm{ml}$ water addition. Most decay with $52.5 \%$ maximum at $120 \mathrm{ml}(104 \%$ moisture content) occurred with the malt extract culture. The subsequent decrease of mass loss may be caused by too high moisture content. 
Fungi are able to transport water by their mycelia from a moisture source to neighbouring wood (Schmidt 2006). Figures 3 and 4 show that the final moisture content of the bamboo samples was not influenced by the different initial liquid additions. Obviously, both fungi did not transport water from vermiculite to the samples. Presence of the metal ring between vermiculite and sample could not be the reason because $C$. puteana could moisten the Scots pine wood. Figure 4 (bottom) shows that moisture content increased up to $218 \%$ u parallel to water addition. Subsequently, mass loss decreased because of too much water in the wood.

The vitality test after 32 weeks of incubation proved living mycelium in all culture vessels (Fig. 5). Because fruit bodies were not grown in the jars, survival was not due to resistant spores. Thus, it can be deduced that mycelia were active over the whole culture period.

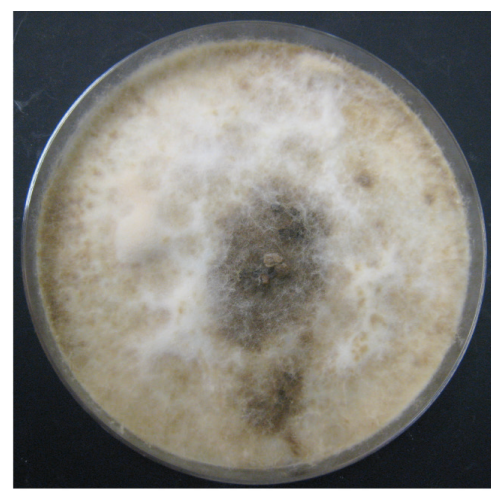

(a)

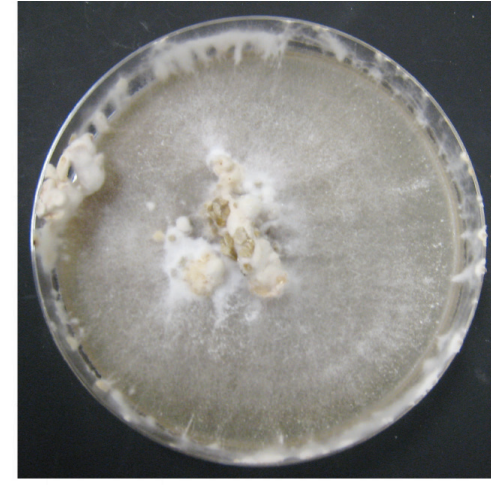

(b)

Figure 5. Vitality test on agar after vermiculite incubation.

(a) Coniophora puteana. (b) Schizophyllum commune.

Schmidt et al. (2011) assumed that high bamboo mass loss by C. puteana and S. commune in the fungus cellar test was mainly caused by the moisture conditions and lesser by components from the unsterile soil. The vermiculite test as pure-culture experiment in closed vessels did not show a significant effect of moisture content and nutrient addition on bamboo degradation. Thus, bamboo degradation in nature may be also influenced by better air conditions, soil minerals or vitamins from soil bacteria. Already Leutritz (1946) demonstrated that soil serves as water holding substrate and provides substances from the soil. The influence of minerals and vitamins on soft rot was reported by Worrall and Wang (1991) and Worrall et al. (1991). However, the small differences of mass loss among the bamboos, fungi and test parameters make further discussion problematic. The fungi had been selected due to three reasons: $S$. commune is very common on bamboo and the experimental strain was isolated by us from bamboo; $C$. puteana is an obligatory test fungus in the European standard EN 113; third, it was hoped to explain the influence of moisture content and nutrients in the fungus cellar test. However, with regard to wood, the decay results with $C$. puteana and P. sylvestris samples (Fig. 4) show the suitability of the proposed technique for degradation studies. Assumably, our vermiculite method will also show greater fungal activity against bamboo if more aggressive fungi such as Pleurotus ostreatus and Trametes versicolor (Schmidt et al. 2011) are used.

\section{CONCLUSION}

The preserving jar/vermiculite technique is suitable for fungal degradation studies of lignocelluloses as shown by the mass loss of Pinus sylvestris wood by Coniophora puteana. Adding $2 \%$ malt extract solution till wood moisture content around $100 \%$ provided high mass loss within 32 weeks of incubation. However, with regard to bamboo, interpretations are problematic due to the low activity of both fungi on bamboo.

\section{ACKNOWLEDGEMENTS}

We thank Wolfgang Eberts (Bamboo Centre Germany) and Christoph Tönges (CONBAM, Germany) for providing the bamboo and Marie-Therese Lenz for technical help. 


\section{REFERENCES}

Abdurachim, M.R.A. 1964. Bamboo preservation in Indonesia. Rimba Indonesia 9(1): 66-76.

Adaskaveg, J.E.; Blanchette, R.A.; Gilbertson, R.L. 1991. Decay of date palm wood by white-rot and brownrot fungi. Canadian Journal of Botany 63(3):615-629.

Becher, G.; Kaune, P. 1966. Einflüsse beim Holzabbau durch Moderfäulepilze in Erde. Material and Organisms $1(3): 201-220$.

Curling, F.C.; Clausen, C.A.; Winandy, J.E. 2002. Experimental method to quantify progressive stages of decay of wood by basidiomycete fungi. International Biodeterioration \& Biodegradation 49(1):13-19.

EN 113. 1996. Determination of the toxic values of wood preservatives against wood destroying Basidiomycetes cultured on agar medium. Beuth, Berlin.

Kaune, P. 1970. Bedingungen für das Prüfen mit Moderfäulepilzen im Vermiculit-Eingrabe-Verfahren. Material and Organisms 5(2):95-112.

Kim, J.J.; Lee, S.S.; Ra, J.B.; Lee, H.; Huh, N.; Kim, G.H. 2011. Fungi associated with bamboo and their decay capabilities. Holzforschung 65(2): 271-275.

Leutritz, J. 1946. A wood-soil contact culture technique for laboratory study of wood destroying fungi, wood decay and wood preservation. Bell System Technical Journal 25(1): 102-135.

Liese, W. 1959. Bamboo preservation and soft-rot. Food and Agriculture Organization Report to the Government of India, 1106, $36 \mathrm{pp}$.

Liese, W. 1985. Bamboos - biology, silvics, properties, utilization. Schriftenreihe Gesellschaft für Technische Zusammenarbeit, Eschborn, 180, 132 pp.

Liese, W.; Kumar, S. 2003. Bamboo preservation compendium. International Network for Bamboo and Rattan, Beijing, China, Technical report 22, $231 \mathrm{pp}$.

Ma, X.; Jiang, M.; Qin, D. 2010. The invasion channels of damage fungi in bamboo lumber.

International Research Group on Wood Preservation, Stockholm, IRG/WG 10-10712, 7 pp.

Mohanan, C. 1997. Diseases of bamboos in Asia. International Development Research Centre, New Delhi.

Peylo, A. 2001. Schnellanalyse von Holzschutzmitteln. Schützen \& Erhalten. 3p.

Schmidt, 0. 2006. Wood and tree fungi. Springer, Berlin.

Schmidt, O.; Liese, W. 1978. Biological variations within Schizophyllum commune. Material and Organisms 13(3): 169-185.

Schmidt, O.; Wei, D.; Liese, W.; Wollenberg, E. 2011. Fungal degradation of bamboo samples. Holzforschung 65(6): 883-888.

Suprapti, S. 2010. Decay resistance of five Indonesian bamboo species against fungi. Journal of Tropical Forest Science 22(3): 287-294.

Worrall, J.J.; Wang, C.J.K. 1991. Importance and mobilization of nutrients in soft rot of wood. Canadian Journal of Microbiology 37(11): 864-868.

Worrall, J.J.; Anagnost, S.E.; Wang, C.J.K. 1991. Conditions for soft rot of wood. Canadian Journal of Microbiology 37(11): 869-874. 